\title{
The Starter Activity of the Lesson; Considerable Categories and Dynamics
}

\author{
* Dr. Anjum Naz, Associate Professor \\ ** Dr. Abida Nasreen, Associate Professor (Corresponding Author) \\ *** Dr. Sumaira Rashid, Assistant Professor
}

\begin{abstract}
Lesson planning is an established skill and teacher trainers are giving it considerable attention during teacher training. The most challenging part of a lesson plan is a starter activity. This activity is not entirely neglected but still not well explored and researched. The purpose of this research study was to discover the categories of starter activities planned by the teachers teaching the matching subjects at the same level while having a contrasting background and training i.e. developed and developing countries' teachers. Secondary school teachers from UK and Pakistan were selected conveniently. An inventory was used to collect data from the research participants. A focus group was also conducted using 'Teams'. A phenomenological investigation leads to considerable findings. The aim of starter activities is the same though the categories and extent of use are different. Further, it was established that teachers used starter activities as a tool and bait to engage students, create a friendly classroom environment, and arouse the curiosity of the students however some might be using the same as an opportunity to smile and achievement for everyone to ensure inclusion. It was suggested that considerable importance should be given to the subject and prospective teachers should be provided with an exhaustive list of starter activities categories to enable them to plan and deliver effectively.
\end{abstract}

Keywords: Lesson, Planning, Trainers, Starter Activities

Introduction

The idea of this study originated from one discussion during the teacher training classroom, where teachers were discussing the problems and challenges of making an effective lesson plan, the discussion started from the elements of the lesson plan, obviously the first element discussed at the start, all 25 teachers agreed on the point that the start of the lesson plan is most challenging and we need to invest maximum time and energy in this area. They all mentioned multiple reasons based on their personal experiences e.g. good start keeps students hooked, the mood of both students and teachers remain better throughout the lesson, both could feel more engaged and motivated and meaningful, relevant and challenging start can improve learning. The researchers, being part of the group, enjoyed the discussion and decided to enlist and consolidate the ideas of lesson starters. The later researchers reviewed relevant literature and found that many empirical research studies supported the above-mentioned reasons provided by the teachers. (Sievert, Cuvo \& Davis, 1988).

Educational experts and research studies both are supporting the idea of using traditional and novel thought-provoking activities as a starter (Algozzine, Browder, Karvonen, Test, \& Wood, 2001). That should have been planned with wisdom following students' potential and age etc. (Okey \& Gagne, 1970).

Starter activities can also be called bell work, or focusing activities, a predictable, formatted, content-based beginning of class activity ( Schisler, 2020)) and these can be utilized to achieve instructional goals. The beginning of class might be used to create a sense of purpose for the lesson and to connect content to students' lives (Weber, 2019). The class might start with a repeating set of slides, asking students to sequence steps or sketch a content-related drawing (Honeycutt, 2019).

\section{Review of Related Literature:}

The first impression is the last, it is a common saying, and most people believe it although it is not true in most cases, as impression built gradually (Tylor, 1949; Browder, 2001) and vice versa. Every

\footnotetext{
* Institute of Education and Research, University of the Punjab, Lahore

** Institute of Education and Research, University of the Punjab, Lahore

*** Institute of Education and Research, University of the Punjab, Lahore
} 
teaching lesson is a new start and the starter of the lesson is significant to set the tone of the lesson. A lesson generally has three parts i.e. start, mid, and end. The start of the lesson is significant as it is a phase of engagement, while the mid of the lesson be meaningful for the engaged minds and the end of the lesson is plenary one where students reflect either they were engaged or not (Stewart, Van Kirk, \& Rowell, 1979).

A common saying is 'you never get a second chance to make a first impression'. Ward (1988) endorsed the fact that a person needs to use his self-determination to accomplish the task but starting

The task is a more challenging thing. In teaching sessions, only a prompt arrangement would keep students' concentration attentive throughout the lesson. In the teaching process, a lesson plan of the teacher had a central point following all stakeholders i.e. teacher performs, students respond and the school manager monitors the process (Novak, 1990). While the start of the lesson is considered the most challenging part of the lesson plan (Wehmeyer, Agran, \& Hughes, 2000) although the other considerations such as learning objective, differentiation, and literacy aspects are also not very easy to maintain but the starter activity acts as a foundation stone of the learning (Field \& Hoffman, 1994). Experienced teachers generally use their professional wisdom and professional experience to plan the starter activity and always keep a level and previous knowledge of students in view (Arnaudin, Mintzes, Dunn \& Shafer (1984). Some teachers divide their lessons into five parts based on the purpose of that part i.e. starter as an attention call, initial introduction of the lesson as an appetizer, middle part the main lesson for teaching novel concepts, second last part of the lesson as a summary and last as plenary to assess the achievement of objectives (Kaplan \& Cannon, 2001).

The starter of the lesson means any picture, idea, video, or activity which is being used to break the ice, to grab the attention of the students (Cliburn, 1986)). Starter activity is multipurpose, grabs attention as a motivator strategy, check previous knowledge, checks preparedness and willingness to learn. Some other purposes are stated by Capel, Leask, Marily and Younie, (2016) i.e. starter activity is used to set the stage, engage the learners, grab the attention (Martin, 1991), float an idea, give a clue, provide a sense of the direction, check the previous learning or on a lighter note would be a foundation stone of friendly atmosphere in the classroom (Carnine, 1997).

The major purpose is to hook up the students with the task which not a simple task (Novak, 1980). Lesson planning involves professional wisdom, teaching experience, content knowledge, instructional skill, and commitment (Agran, Snow \& Swaner, 1999).

Stewart, Van Kirk, \& Rowell, (1979) states that most teachers don't take starters seriously unless they have urgency of observation or demonstration of their experience for promotion or grabbing a new position, it is a cruel reality but supported by empirical evidence (Wehmeyer, Agran, $\&$ Hughes, 2000). There are many empirical pieces of research available that had proved the fact that monotonous lesson start is boring and less motivating (Starr \& Krajcik, 1990). The teacher needs to motivate the students and lead them to the lesson of the day with a meaningful starter activity or idea.

Some teachers use starter activity to set standards and make it clear, how the lesson will progress and what are the standards and behavior expectations. While others use to tell the objectives of the lesson only (Carnine, Filbert, \& Kameenui, 1997). What comes first set the tone, is a true notion in terms of the students and teacher behavior during the whole lesson (Wehmeyer, 1996).

A clear, interesting, relevant, and engaging starter activity can ensure and maximize learning throughout the session. The teacher mostly has very good content knowledge and even presentation skills too (Novak, 1991) but if the start of the lesson would not be engaging, student's attention would be distracted (Capel, Leask \& Younie, 2016). A boring and dull start can spoil the impression of the teacher, while the teachers need to inspire the students throughout their lesson (Wehmeyer \& Schwartz, 1998). Engagement theory claimed that students must be kept engaged in meaningful activities (Kearsley, 1997; Shneiderman, 1994, 1995; Shneiderman et al, 1998). A constructivist approach also supports the phenomena as it also considers student collaboration important for learning (Lucy et al, 1991).

Kaplan \& Cannon (2001) stated that the teacher is a decision-maker and he needs to decide how to collaborate on the activities during the lesson. The teacher could plan his starter activity with the help of starter cards to deal with the individual differences in the class (Sievert, Cuvo, \& Davis, 1988). Starter cards contain the curriculum content and teacher use them to facilitate differentiated learning experience (Kaplan \& Cannon, 2000) 
Every teacher has a unique background, expertise, skill, and planning skills (Kauffman, 1996). So, the starting of the lesson would also definitely be divergent (Cooper \& Browder, 1998). However, the purposes are broadly similar i.e. focus on learning, thought-provoking for students, and engaging them (Test, Karvonen, Wood, Browder \& Algozzine, 2000). Kaplan \& Cannon (2001) has classified starter cards into six categories:

1. Motivation cards stimulate interest by using prior knowledge or personal experience.

2. Input cards contain open-ended questions or general quotations from textbooks or relevant literature.

3. Output cards are used for closure to enhance research skills or to introduce mini-projects.

4. Extension cords are used for highlighting the connection of the topic under study with related fields to enhance students' interdisciplinary approach.

5. Independent study cards provide guidelines and information about self-directed learning about the topic.

6. Thinking skill cards provide a stimulus for higher-level thinking and are used to enhance student's comparative, discriminative, and classification abilities, which would later help them to make informed inductive decisions and judge the strength of arguments.

\section{Classification of Starter Activities}

Starters are broadly categorized as regular starter and unique. The regular starters are most relevant to the field under study e.g. art teacher using a collection of art would be an example of a regular starter. While the unique starters as the name indicate would or may not be relevant to that particular lesson, or field of study e.g. showing an interesting image, floating a controversial idea or role-playing, etc. The purpose of the first one to provide the initial details about the lesson while the purpose of the second category is to engage students. A good start is that which makes the student think and respond. Types of Starter Activities:

There are many types of starter activities. Some are listed in this research. This is not an exhaustive list of starter activities, as every subject has its unique requirements. The level of student is also an important factor while the unique background, knowledge, skill, and experience of teachers had an impact on their selection of starter activity (Wehmeyer, Agran \& Hughes, 2000).

i. Use of Images/pictures (still \& motion): The images can be used in our educational setting where we all are using technology easily; visual images can grab the attention of students as a common saying is "a picture is worth of thousand words". It could be a simple picture, abstract art or a situation or an event that followed a question. The selection of images is a sensitive matter; mostly teachers have the potential to select a relevant image to check the previous knowledge of the learners.

ii. Let's create: A starter could be a simple one, just give a piece of paper and ask them to draw something or make something interesting on the paper or with the paper something three dimensional, at a primary level a modeling dough or blocks can be used while at a secondary level jigsaw puzzle could be a good option.

iii. Ask questions: The questioning game can be used as a starter. The teacher chooses some events and asks students to ask a series of questions. It can be used to activate students before the lesson.

iv. Open mystery bag: In this interesting activity, the teacher brings a small bag with some relevant material to the lesson of the day, and gives it to the student to guess, what might be in the bag; it could create an amusing situation because of students' responses.

v. Graphic organizer: KWL chart includes three circles in which students are required to write, what they know, want to know, and known to them or some other organizers may be used.

vi. Pass the parcel: A box containing a statement about the lesson used, every student passes it to the next and everyone is picking and reading a statement and decides either the statement is true or false. This activity can strengthen previous knowledge.

vii. Memory Game: The teacher shows a list of words to the students for one minute or longer and asks them to recall the words and write in order.

viii. Odd one out: The teacher shows four statements about the topic and students need to select one that is odd or less relevant to the lesson. 
ix. The Answer Is: The teacher asks a question and shows s number of pictures and students need to pick an answer, or one picture with several objects and students need to pick a relevant one.

x. Game Shows: All games can be converted into a starter of the lesson e.g. wheel of fortune, who wants to be millionaire and drawing competition etc.

\section{Objectives of the study}

The objectives of the study were to:

1. Find out major categories of starter activities used by teachers teaching in the UK and Pakistan.

2. compare and contrast the starter activities ideas to sort out the difference of selection and preferences

3. Explore what are the purposes of teachers to use the starter activity.

\section{Research Questions}

This research study is an endeavor to answer these questions:

1. Either teacher need to plan a starter activity?

2. What are the purposes of the starter activity?

3. What are the different types of starter activities?

4. Is there any difference in the choice of starter activities that exist among the teachers teaching the same subject at matching levels in developed and developing countries?

\section{Significance of the study:}

Teaching is a noble profession, while teachers are considered as the main person who had a visible impact on teaching strategies in the use and learning of the students. Teachers plan lessons to organize their teaching and ensure effective learning, lesson planning is not only a skill rather it is an attitude without which effective planning is not possible. The most challenging component of the lesson plan is the starting point as teachers want to engage the learner throughout the lesson. The literature on lesson planning is available but scarce on starter activity planning because most of the teachers and teacher trainers consider it a matter of experience. This research is an endeavor to highlight the significance of starter activity and aimed to document the types of starter activities. Further, the findings of the study would be useful for the teachers and teacher trainers to implement in practical lesson planning to ensure student engagement.

\section{Methodology of the Study:}

The nature of the study is qualitative and a phenomenological investigation was expended to get an in-depth insight into the phenomena. The literature was reviewed extensively to find out the categories of starter used across the globe, based on the available empirical research studies, an inventory of starters was prepared and sent to the participants who were selected against the preset criteria of sample selection, two open-ended questions were added at the end of the inventory to get the opinion of teachers about the effectiveness of the best and most used starter activity. The target population of the study was teachers teaching social science subjects at the secondary level in UK and Pakistan.

One of the researchers was visiting the UK for her postdoc research project, therefore, UK, specifically England \& Wales were conveniently selected to get data from the secondary school teachers, while the other team members were present in Pakistan, (specifically, District Lahore, Sargodha \& Multan from the province of Punjab were conveniently selected). The data was collected from these districts to have diverse types of data. The researcher invited social sciences' teachers who had completed their teacher training and having at least two years of teaching experience at the secondary level in the UK and Pakistan, forty teachers from each country were invited to participate in the study, but from UK twenty-three (23) teachers agreed to participate while from Pakistan thirtytwo (32) teachers participated in the study, in this way fifty-five (55) teachers agreed to write a response against inventory. The volunteers were informed about the objectives and background of the study and once they agreed to participate, the consent form was sent along with an inventory of starter categories via email. The researcher requested participants to return the inventory in ten days and once all participants returned the inventories, those were analyzed to find out the trend of starter activity in different cultures. The frequencies and percentages of responses were calculated to present empirical pieces of evidence of the trends of starter activity. 
The same participants were invited to participate in a focus group discussion session to sort out the effectiveness of different categories of starter activities at the secondary level. The focus group was conducted using 'Teams'. A link was shared with the participants. The time and date of the session were set with mutual agreement, while nine (09) teachers from the UK and thirteen (13) from Pakistan managed to attend the focus group discussion. The focus group discussion lasts for two hours and was recorded with the permission of participants which was later transcribed and edited for further consolidation.

\section{Findings of the Study:}

The inventory was used to get three categories of responses from the participant teachers' i.e.

1. mostly used category

2. best one

3. Difficult to plan.

The inventory was sent with clear instruction to the participants, need to provide three kinds of responses in the form of tick $(\checkmark)$ encircle $(O)$, and cross $(X)$ signs. They mark a sign of tick $(\checkmark)$ on the starter activities which they mostly use in their classroom. Further, they need to encircle those starter's activities which they think are best for secondary level, and lastly, they need to put a cross sign (X) against those starter categories which they think would be more difficult for them to use. The following Table presents frequencies and percentage of most used, best and difficult category of the starters by the teachers of UK and Pakistan.

Table 1:

Categories of starters and responses taken from the teachers in the UK and Pakistan.

\begin{tabular}{|c|c|c|c|c|c|c|c|c|c|c|c|c|c|}
\hline \multirow{3}{*}{$\begin{array}{l}\mathrm{Sr} \\
\#\end{array}$} & \multirow{3}{*}{$\begin{array}{l}\text { Categories of } \\
\text { starters } \\
\text { Approx. }\end{array}$} & \multicolumn{4}{|c|}{ Mostly used } & \multicolumn{4}{|c|}{ Best one } & \multicolumn{4}{|c|}{ Most difficult } \\
\hline & & \multicolumn{2}{|c|}{ UK } & \multicolumn{2}{|c|}{ Pakistan } & \multicolumn{2}{|c|}{ UK } & \multicolumn{2}{|c|}{ Pakistan } & \multicolumn{2}{|c|}{ UK } & \multicolumn{2}{|c|}{ Pakistan } \\
\hline & & $\%$ & $\mathrm{~F}$ & $\%$ & $\mathrm{~F}$ & $\%$ & $\mathrm{~F}$ & $\%$ & $\mathrm{~F}$ & $\%$ & $\mathrm{~F}$ & $\%$ & $\mathrm{f}$ \\
\hline 1 & Direct Start & 25 & 6 & 75 & 24 & 4.1 & 1 & 40.6 & 13 & 25 & 6 & 9.4 & 3 \\
\hline 2 & $\begin{array}{l}\text { Stating } \\
\text { Objectives }\end{array}$ & 50 & 12 & 81.3 & 26 & 75 & 18 & 43.7 & 14 & 0 & 0 & 0 & 0 \\
\hline 3 & $\begin{array}{l}\text { Use of image/ } \\
\text { picture/video }\end{array}$ & 75 & 18 & 25 & 8 & 79.1 & 19 & 43.7 & 14 & 0 & 0 & 12.5 & 4 \\
\hline 4 & Gameshow & 25 & 6 & 21.9 & 7 & 87.5 & 21 & 71.9 & 23 & 33.3 & 8 & 87.1 & 28 \\
\hline 5 & 15 question & 29.1 & 7 & 6.6 & 2 & 79.2 & 19 & 65.6 & 21 & 37.5 & 9 & 53.1 & 17 \\
\hline 6 & Odd one out & 37.5 & 9 & 0 & 0 & 45.8 & 11 & 81.3 & 26 & 8.3 & 2 & 28.1 & 9 \\
\hline 7 & Memory game & 70.8 & 17 & 15.6 & 5 & 95.8 & 23 & 75 & 24 & 0 & 0 & 12.5 & 4 \\
\hline 8 & Pass the parcel & 45.8 & 11 & 6.6 & 2 & 54.2 & 13 & 28.1 & 9 & 45.8 & 11 & 84.4 & 27 \\
\hline 9 & Mystery bag & 20.8 & 5 & 0 & 0 & 62.5 & 15 & 43.7 & 14 & 50 & 12 & 81 & 26 \\
\hline 10 & The answer is; & 62.5 & 15 & 25 & 8 & 62.5 & 15 & 75 & 24 & 16.6 & 4 & 15.6 & 5 \\
\hline 11 & Let's create & 54.1 & 13 & 18.7 & 6 & 79.2 & 19 & 56.2 & 18 & 20.8 & 5 & 46.9 & 15 \\
\hline 12 & $\begin{array}{l}\text { Graphic } \\
\text { organizer }\end{array}$ & 33.3 & 8 & 12.5 & 4 & 87.5 & 21 & 78.1 & 25 & 54.2 & 13 & 87.5 & 28 \\
\hline
\end{tabular}

\section{Mostly used starter activity}

The above table and statistics show that the situation is contrasting. In UK, images, pictures, and videos (75\%) are used as starter activity while in Pakistan, stating objectives $(81.3 \%)$ is considered as a starter activity. Access to resources and technology might be one reason for this difference.

\section{Considered as Best starter:}

Memory game (96\%), game show (88\%), graphic organizers (88\%), lets' create (79\%), asking questions (79\%) are chosen as best starter activities by UK teachers while Pakistani teachers chose memory game (75\%), game show (72\%), graphic organizer $(78 \%)$ and odd one out (81\%) as best starter activities.

\section{Considered as most difficult activity:}

The mystery bag (50\%) and graphic organizers (54\%) are mentioned as most difficult to plan by UK teachers but Pakistani teachers stated that graphic organizer (88\%) pass a parcel $(85 \%)$ and game show $(87 \%)$ are difficult to plan as starter activities.

\section{Discussion with the teachers:}

The researcher presented the result of the inventory after simple statistical analysis i.e. calculated percentages and frequencies to exhibit the trend regarding the use of particular activity in the UK and Pakistan and then initiated the discussion on objectives and planning of effective starter activity. 
The second part of the study starts with a focus group. The focus group discussion was recorded, transcribed, and edited for grammatical mistakes and to remove the ambiguities with the help of volunteer participants. The researcher consolidated the transcribed file and reviewed the same to identify the keywords which were later merged in four specific themes regarding the objectives of starter activity i.e. maintain an interest, relating to the subject, suitable for cognition, give a sense of achievement to students, and enhance their curiosity.

\section{$i$. Interesting and the engaging start of the lesson:}

The purpose of the starter activity is to engage the learners and an interesting start would be helpful for the teachers to maintain the pace of the lesson. The teachers agreed on the idea of making starter activity as a joyful activity and one teacher suggested "A well-planned activity can make the day of both teacher and students; I mostly prefer to choose an activity which can bring a smile to our fact at the start of the lesson' (UKT \# 5).

ii. Relevant to the subject:

The starter activity is an opportunity to give an interesting start to the topic of the day, any relevant, interesting, or anomalous fact and figures about the topic may be used as a starter activity. One teacher stated in my opinion, a major purpose of starter activity is to start a topic, I use archives for collecting interesting facts about the topic which always proved to be an effective starter for me and my class' (PAKT \# 2)

iii. $\quad$ Suitable to students' cognitive level:

An important principle of lesson planning is relevance i.e. a lesson should be planned keeping in view the abilities and cognitive level of students, so the starter activity is not an exception. A participant of the study agreed on the point that starter activity must be slightly below the cognitive level. One participant of the discussion explained that 'a starter activity planning should be following the cognitive level of the students but at the same time; I choose to keep it easy too' (UKT \# 6).

iv. $\quad$ Gives sense of achievement:

The starter activity is not planned to follow the objectives of the lesson but to give a sense of achievement to everyone in the class. A teacher mentioned "I plan starter activity to get the answer from the most silent students and from those who are lagging in the subject or struggling to understand the subject under study, the sense of achievement is important to motivate students and encourage their participation by providing an auspicious opportunity (PAKT \# 1).

v. $\quad$ Enhance curiosity:

The starter activity may be used as a curiosity generator that arouses students urge to know about the subject. One participant teacher shared his personal experience ' I presented a challenging situation related to the subject in the classroom at the start of the lesson and invited students to suggest different ways, then I narrated possible ways to resolve the problem, the students' curiosity was at the peak, they want to get more knowledge about the topic as they need to suggest the solution to the problem presented in the start, in this way their curiosity kept them engaged throughout the lesson' (UKT \# 2).

\section{Tips for effective starter planning:}

The focus group discussion on the topic of the starter was a very productive one as teachers discussed different ideas and feasibility of ideas shared their practices and experiences and suggested some common grounds for planning an effective starter activity as they all are agreed on the notion that the starter activity can be used as bait. Some valuable suggestions discussed are as follows:

i. $\quad$ Keep your starter activity very simple and accessible

ii. The good starter can be repeated many times by just changing content

iii. The students' skill level and ability should be kept in view.

iv. Don't take starter activity casually

v. Ask a question about the starter

vi. Invest time, energy, and enthusiasm in both planning and execution of starter activity

Vii Use the reputed archive to get novel ideas

viii. A current event, incident, and interesting news may be discussed as a starter

ix. $\quad$ Keep starter activity open-ended

$\mathrm{x}$. Ensure all students in the class can feel a sense of inclusion

xi. Make starter a little bit extended by increasing the difficulty level at the end 
xii. The starter can be of both categories relevant to previous or present lesson or very irrelevant to any lesson when it is used to break the ice with students.

xiii. Make your starter an appetizer for the rest of the lesson

xiv. Make starter as a trigger of long-term memory by relating with the concept.

Conclusion of the study:

The literature and discussion with the teachers established that the significance of starter activity is massive. However, the planning of the starter activity is a challenging task. There is a range of categories and ideas are available which can be used to plan a starter activity to engage students. The purpose of the starter activity might be to engage, motivate, and arouse the curiosity of the students and to create a friendly environment in the classroom. A teacher who has considerable experience of teaching suggested that starter activity could be used as bait to keep students active and at the same time, it ensures inclusion where everyone got a sense of achievement and could feel this sense of achievement.

\section{Recommendations:}

The findings of the study recognized the significance of starter activity and established a notion that prospective teachers need good training to plan a lesson and specifically, they should learn to develop lesson starter activities. It is an effective and engaging classroom strategy to use starter activities in the classrooms. The experienced teachers in the field could play a very effective role in suggesting feasible ways and ideas implemented in the classroom. It is also recommended that teacher training institutes and experts conduct more researchers to explore the concept and prepare an exhaustive list of starter activities suitable for use at different levels in a range of subjects.

\section{References}

Agran, M., Snow, K., \& Swaner, J. (1999). Teacher perceptions of self-determination: Benefits, characteristics, strategies. Education and Training in Mental Retardation and Developmental Disabilities. 34, 293-30.

Algozzine, B., Browder, D., Karvonen, M., Test, D. W., \& Wood, W. M. (2001). Review of Educational Research. 71(2), 49-108.

Arnaudin, M. W., Mintzes, J. J., Dunn, C. S., \& Shafer, T. S. (1984). Concept mapping in college science teaching. Journal of College Science Teaching, 13(11), 117-121.

Browder, D. M. (2001). Curriculum and instruction for students with moderate and severe disabilities. New York: Guilford Press.

Capel, S., Leask. Marily, L., \& Younie, S. (2016). Learning to teach in the secondary school; a companion to school experience' $7^{\text {th }}$ Edi. London. Routledge Tylor \& Francis publishers.

Carnine, D. W. (1997). Bridging the research-to-practice gap. Exceptional Children. 63, 513-521.

Carnine, D. W., Filbert, J., \& Kameenui, E. J. (1997). Direct instruction reading (3rd ed.). Upper Saddle River, NJ: Prentice-Hall.

Cliburn, J. W. (1986) Using concept maps to sequence instructional materials. Journal of College Teaching, 16(3), 377-379.

Cooper, K. J., \& Browder, D. M. (1998). Enhancing choice and participation for adults with severe disabilities in community-based instruction. Journal of the Association for Persons with Severe Handicaps, 23, 252-260.

Field, S., \& Hoffman, A. (1994). Development of a model for self-determination. Career Development for Exceptional Individuals, 17, 159-169.

Honeycutt, Barbi (2019). Three Focusing Activities to Engage Students in the First Five Minutes of Class. Faculty Focus. https://www.facultyfocus.com/articles/blendedflipped-learning/three-focusing-activities-engage-students-first-five-minutes-class/

Kaplan, S., \& Cannon, M. W. (2001). Curriculum Starter Cards; Developing Differentiated Lessons for Gifted Students. Texas, Prufrock Publishers.

Kauffman, J. M. (1996). Research to practice issues. Behavioral Disorders, 22, 55-60.

Lucy, E., Lucy, J., Allen, J., Graham, M., \& Pankratius, B. (1991). Get your hands on concept mapping. (A workshop presented at the National Science Teachers Association Annual Convention, Houston, TX, March 30, 1991).

Martin, D. J. (1991).The effect of concept mapping on biology achievement of field-dependent students. Unpublished doctoral dissertation, Georgia State University, Atlanta, GA. 
Novak, J. (1991). Clarify with concept maps: A tool for students and teachers alike. The Science Teacher, 58(7), 45-49.

Novak, J. D. (1980). Handbook for the learning how to learn program. Ithaca, NY: New York State College of Agriculture and Life Sciences, Cornell University, Department of Education, 103 Stone Hall.

Novak, J. D. (1990). Concept mapping: A useful tool for science education. Journal of Research in Science Teaching, 27(10), 937-949.

Okey, J. R. \& Gagne, R. M. (1970). Revision of a science topic using evidence of performance on subordinate skills. Journal of Research in Science Teaching, 7(4), 321-325.

Schisler, L. (2020). A Starter Activity to Begin Any Class. Faculty Focus. Magna publications.

https://www.facultyfocus.com/articles/effective-teaching-strategies/a-starter-activity-to-begin-anyclass/

Sievert, A. L., Cuvo, A. J., \& Davis, P. K. (1988). Training self-advocacy skills to adults with mild handicaps. Journal of Applied Behavior Analysis, 21, 299-309.

Starr, M. L. \& Krajcik, J. S. (1990). Concept maps as a heuristic for science curriculum development: Toward improvement in process and product. Journal of Research in Science Teaching, 27(10), 987-1000.

Stewart, J., Van Kirk, J., \& Rowell, R. (1979) Concept maps: A tool for use in biology teaching. American Biology Teacher, 41(3), 171-175.

Test, D. W., Karvonen, M., Wood, W. M., Browder, D., \& Algozzine, B. (2000). Choosing a selfdetermination curriculum. Teaching Exceptional Children, 33(2), 48-54.

Tyler, R. W. (1949). Basic principles of curriculum and instruction. Chicago, IL: The University of Chicago Press.

Ward, M. J. (1988). The many facets of self-determination. NICHCY transition summary: National Information Center for Children and Youth with Disabilities, 5, 2-3. This is a Booklet.

Weber, Wolfgang S (2019). The Most Crucial Two Minutes of Class. Faculty Focus. https://www.facultyfocus.com/articles/effective-teaching-strategies/the-mostcrucial-two-minutes-of-class/

Wehmeyer, M. L. (1996). Self-determination in youth with severe cognitive disabilities: From theory to practice. In Powers, L. E., Singer, G. H. S., Sowers, J. (Eds.). On the road to autonomy: Promoting self-competence for children and youth with disabilities (pp. 1736). Baltimore: Paul H. Brookes.

Wehmeyer, M. L., Agran, M., \& Hughes, C. (2000). A national survey of teachers' promotion of selfdetermination and student-directed learning. Journal of Special Education, 34, 58-68.

Wehmeyer, M. L., \& Schwartz, M. (1998). The self-determination focus on transition goals for students with mental retardation. Career Development for Exceptional Individuals, 21, 75-86.

https://books.google.co.uk/books?hl=en\&lr=\&id=wAEyDB1UX0IC\&oi=fnd\&pg=PR5\&dq=use+of $+\mathrm{s}$ illy+starter+activity+in+lessons\&ots=0bFLVqyxUB\&sig=97k2ebLV7tVGsjN3ttF1kR6b7zw \&redir_esc $=\mathrm{y} \# \mathrm{v}=$ onepage $\& \mathrm{q} \& \mathrm{f}=$ false

https://books.google.co.uk/books?hl=en\&lr=\&id=ell9AgAAQBAJ\&oi=fnd\&pg=PA103\&dq=lesson+ plan+starter+activity+\&ots=1H2_ncic35\&sig=LksbP1mLxRHbQNKfYG32aefz7w8\&redir_es $\mathrm{c}=\mathrm{y} \# \mathrm{v}=$ onepage $\& \mathrm{q}=$ lesson $\% 20$ plan $\% 20$ starter\%20activity $\& \mathrm{f}=$ true

https://books.google.co.uk/books?hl=en\&lr=\&id=86zDCwAAQBAJ\&oi=fnd \&pg=PA108\&dq=lesson + plan+starter+activity+\&ots=kgBGeeK0o5\&sig=rkGc0DOGao2nchrMHUsNr9mNfJA\&redi r_esc $=\mathrm{y} \# \mathrm{v}=$ onepage $\& \mathrm{q}=$ lesson $\% 20$ plan $\% 20$ starter\%20activity $\& \mathrm{f}=$ false 